\title{
SYMPTOMATIC ARTERIAL HYPERTENSIONS
}

\author{
Marinov L. \\ Second specialized pediatric clinic of cardiology, rheumatology, nephrology, \\ gastroenterology and intensive care, University hospital "St. Marina", Varna
}

\section{Reviewed by: Assoc. Prof. Iv. Galabov}

\begin{abstract}
Arterial hypertension (AH) is one of the most frequent diseases of the cardio-vascular system. The medico-social importance of the disease is determined by its high frequency, including $25 \%$ of the mature people. AH is a main risk factor for the development of atherosclerosis and the connected with it cardiovascular and brain-vascular pathology. For years was thought, that $\mathrm{AH}$ during childhood is a rare disease. The contemporary knowledge shows that 5-6\% of the school children are with hypertension. Depending on the etiology, $\mathrm{AH}$ is divided into primary, in which the causes of the high blood pressure are complex and not fully known, and secondary or symptomatic arterial hypertension (SAH), in which the high blood pressure is due to another main disease. It is considered that $\mathrm{SAH}$ represents $15-20 \%$ of the hypertension. As smallest is the age in which are found the high levels of blood pressure, the highest is the probability that this is SAH. In the recent review are shown the most frequent causes for the occurrence of SAH. These are diseases mostly of the urinary system - parenchymal and reno-vasal, of the cardio-vascular system - coarctation of the aorta, persistent arterial canal, lesions of the aortic valve, diseases of the endocrine system - pheochromocytoma, Cushing disease, diseases of the nervous system - tumors, neuroinfections, cranial traumas, iatrogenic hypertension - taking of mineral corticosteroids, anticonception drugs, etc. The main methods for diagnostics and therapeutic strategies for SAH are presented.
\end{abstract}

Key words: symptomatic arterial hypertension, children, diagnosis, treatment

One of the most frequent diseases of the cardio-vascular system is the arterial hypertension (AH). The causes for the raising of the blood pressure (BP) are connected with increase of the peripheral vascular resistance and/or increase of the heart capacity. $\mathrm{AH}$ is one of the main health problems of nowadays life. Its medico-social importance is determined of three main factors:

1. Wide distribution, it includes $25 \%$ of the mature people;

2. Main risk factor for the development of atherosclerosis and the connected with it severe cardio-vascular and brain-vascular pathology;

3. High frequency of brain and cardio-vascular incidents, which have a leading part in the total morbidity, disability and mortality of the population (Bulgaria has a leading place in the frequency of apoplexy and myocardial infarction).

For years was thought, that $\mathrm{AH}$ during childhood is a rare disease. Nowadays is known that it is found in 5-6\% of the school children, as the part of the primary AH increases in the bigger children and adolescence $(1,2)$.

The actual classification of $\mathrm{AH}$ in children and adolescence to 18 years is given in "The Fourth Report on the Diagno-

Address for correspondence:

L. Marinov, Dept. of Paediatrics and Medical genetics, Medical

University of Varna, 55 Marin Drinov str., BG-9002, Varna

e-mail: marinovvs@abv.bg sis, Evaluation, and Treatment of High Blood Pressure in Children and Adolescents", 2004 (tabl.1) (6).

According to the etiology, $\mathrm{AH}$ is divided into primary or essential, in which the reasons for the high BP are complex and not fully known, and secondary or symptomatic hypertension, in which the high BP is due to another main disease. The raised BP is a symptom of the main disease. During childhood approximately $80-90 \%$ of the cases with high blood pressure are due to primary $\mathrm{AH}$.

As smallest is the age in which are found the high levels of blood pressure, the highest is the probability that this is secondary or symptomatic arterial hypertension $(6,9)$. The most frequent causes for $\mathrm{AH}$ in age aspect for the pediatric hypertensiology are shown in table 2 .

The causes for the occurrence of secondary arterial hypertension (SAH) can be different diseases of most of the organs and systems - urinary, cardio-vascular, endocrine, nervous system and so on. In children, as is seen in the table, as younger are they, most often SAH is due to diseases of the urinary and cardio-vascular system and rarely of diseases of the endocrine and nervous system.

In approximately $2 / 3$ of the cases there is a renal disease with involvement of the parenchyma and vessels. Among the most frequent diseases of the urinary system are glomerulonephritis, with nephritic syndrome. In them there is a limited glomerulus filtration with increased reabsorbtion and impediment of sodium and water. Leading place has the acute poststreptococcus glomerulonephritis and also other 
Marinov L.

glomerulopathies, as well as some systemic vasculitis (Schonlein-Henoch disease), in which there is involvement of the kidneys. tension. This is one of the most resistant to the treatment and high-grade symptomatic hypertensions. It is connected with the rennin-angiotensin system. Rennin is a hormone,

Table 1. Classification of AH in children and adolescence according to „, The Fourth Report..., 2004

\begin{tabular}{|c|c|c|c|}
\hline CATEGORY & SBP (mm Hg) & And/or & DBP (mm Hg) \\
\hline Normal & P10 - P90 & And & P10 - P90 \\
\hline \multirow{2}{*}{ Prehypertension } & P90 - P95 & And/or & P90 - P95 \\
\hline & \multicolumn{3}{|c|}{ (all children over 16 years with $\mathrm{BP}$ over $120 / 80 \mathrm{~mm} \mathrm{Hg}$ independently that the levels of $\mathrm{BP}<\mathrm{P}_{90}$ ) } \\
\hline \multicolumn{4}{|l|}{ Hypertension } \\
\hline 1-stage & over P95 $+5 \mathrm{~mm} \mathrm{Hg}$ & or & over P95 + 5 mm Hg \\
\hline 2-stage & over P99 + $5 \mathrm{~mm} \mathrm{Hg}$ & or & over P99 + $5 \mathrm{~mm} \mathrm{Hg}$ \\
\hline
\end{tabular}

Diseases, progressing to renal insufficiency, as chronic pyelonephritis, dysplasias (lower number of nephrons), renal polycystosis, hydronephrosis, etc., also are accompanied with changes of the blood pressure. The increased BP is a symptom also of nephrocalcinosis - precipitation of calcium in the kidney, observed in hyperfunction of

Table 2. Most frequent causes of AH in age aspect.

\begin{tabular}{|c|c|}
\hline \multirow{5}{*}{ Infants } & Thrombosis of the renal artery \\
\hline & Stenosis of the renal artery \\
\hline & Inherited renal malformation \\
\hline & Coarctation of aorta \\
\hline & Bronchopulmonal dysplasia \\
\hline \multirow{3}{*}{ Up to 6 years } & Renal parenchymal diseases \\
\hline & Coarctation of aorta \\
\hline & Thrombosis of the renal artery \\
\hline \multirow{3}{*}{ From 6 to 10 years } & Thrombosis of the renal artery \\
\hline & Renal parenchymal diseases \\
\hline & Primary hypertension \\
\hline \multirow{2}{*}{ Adolescence } & Primary hypertension \\
\hline & Renal parenchymal diseases \\
\hline
\end{tabular}

parathyroid glands, in hypervitaminosis D, continuous immobilization. Kidney tumors, conditions after kidney transplantation can provoke disturbed control of the blood pressure and can lead to the development of symptomatic arterial hypertension. Stenosis, thrombosis and other pathological changes in the renal vessels lead to increase of the level of the blood pressure and development of reno-vasal hyper- which is produced by the cells of the jukstaglomerulus apparatus of the kidney. Rennin takes place in the formation of the hormone angiotensin II, which has the following effects: vasoconstriction, stimulation of the secretion of aldosterone, which impediments the sodium ions in the organism and increases the sense of thirst. The vasoconstriction leads to increase of the peripheral vascular resistance, which directly increases BP. The sense of thirst increases the intake of liquids; the impediment of sodium ions lowers the excretion of water with urine. This leads to enlargement of the plasma volume and increase of the BP. From the renal-vascular diseases, leading to high-grade symptomatic $\mathrm{AH}$, the main part has the stenosis of the renal arteries. They are branches of the abdominal aorta and the stenosis of one or both of the arteries lowers the supply of the kidneys with blood and oxygen. This leads to increased secretion of rennin, which by the described way increases the BP.

Inherited and acquired heart diseases are another component in the etiology of the secondary arterial hypertension coarctation of aorta, persisting arterial canal, aortic insufficiency.

Even rarely, some diseases of the nervous system cause secondary $\mathrm{AH}$. These are tumors, hemorrhages, volume processes, conditions with increased intracranial pressure, encephalitis, poliomyelitis, polyradiculonevritits and brain-cranial traumas.

Between the endocrinopathies we have to mention the hyper function of the thyroid gland, as well as those of the parathyroid gland, of the suprarenal glands - increased level of glucocorticosteroids, mainly cortisol, observed in the disease and syndrome of Cushing, as well as those of the mineral corticosteroids, mainly aldosterone. In these diseases besides the characteristic clinical manifestation, there are signs of arterial hypertension. In the last two cases often there is hormonal active tumor. The pheochromocytoma is a rare tumor, with origin from the suprarenal gland, in which there is extremely high level of catecholamines (adrenalin, noradrenalin), which may cause hypertonic crises, which can be the first manifestation of the disease. 
The intake of medicines, containing mineralcorticoids, glucocorticoids, drugs that imitate the effect of catecholamine and so on, lead to increase of the blood pressure. Recently because of the increased distribution of all kinds of narcotics between the adolescence, the attention is directed to the use of narcotics, therapeutic agents and toxins, which can increase BP. These are cocaine, drugs that inhibit appetite, drugs that stimulate attention. Their use leads to different stages of peripheral vasoconstriction and heart stimulation. The excessive use of sympaticomimetics for the treatment of nasal congestion and especially the oral contraceptives in girls in reproductive ages, are often the cause of iatrogenic $\mathrm{AH}$.

\section{DIAGNOSIS}

The diagnostic approach during childhood requires several measurements of BP, using the methodology for measurement of $\mathrm{BP}(6)$. In the presence of high blood pressure there is need of profound assessment of the condition and establishment of the cause of the BP. As smallest is the child with high blood pressure, the highest is the probability to have SAH. The main task is to find out if this is a primary or secondary $\mathrm{AH}$, as the therapeutic approach is different $(3,4,5)$.

The diagnostic plan is different for low-grade hypertension and high-grade hypertension, which usually is a part of another main disease. Special attention and profound diagnostic investigation must be taken after hypertonic crises. There is a necessity of proper assessment of the high-grade hypertensions and seeking of the etiological moments, with the use of the possible laboratory, image, non-invasive and invasive diagnostic methods - ECG, EchoCG, computer tomography, renovasography, contrast test of the vessels of the CNS and so on $(7,8,10)$.

The treatment of the arterial hypertension is complex. For the primary form in the basis of the therapy are the non-medical approaches - main changes in the way of life nutrition, physical activity, avoiding of risk factor as coffee, alcohol and smoking. In conditions, requiring medical therapy, are used medicines directed to the dilatation of the peripheral vessels (different groups vasodilatators), lowering of the blood volume (diuretics), influence over the sympathic activity.

In the secondary forms the treatment is directed to the main pathology, which caused the increase of the blood pressure. The antihypertensive treatment is conducted according to the accepted scheme for maintenance of low levels of BP, with the aim to protect from the development of vascular and other complications. The main task is the elimination of the cause leading to the increase of the BP. According to the etiological factor is made the treatment strategy. If the cause for the disease is of reno-vasal origin, or tumor, for example pheochromocytoma, the patient is prepared for surgical treatment and operated in the first possible mo- ment. In the other case, when the main cause for the symptomatic hypertension is not surgical, and there is no way of its elimination, a medical treatment is performed for lowering of the BP, near the target levels, with the aim of moving away of the development of complications from the high BP and avoidance of hypertonic crises (5).

In conclusion we must say that the symptomatic arterial hypertensions during childhood are challenge for the pediatrician. In most of the cases there is a need for fast and accurate diagnosis, adequate treatment of the children, especially in life threatening conditions as hypertonic crisis and hypertonic encephalopathy. All the children must be hospitalized and the cause of this condition must be established. This is absolutely needed for the determining of the proper therapeutic strategy. The following of the sick child must be held from the general practitioner and pediatric cardiologist. And not in the last place must be discussed the future professional and social adaptation of these children.

\section{BIBLIOGRAPHY}

1. Маринов Л. Разпространение на артериалната хипертония сред юношите от град Варна.

Педиатрия, 2000, 3: 24- 27.

2. Рахнева Р. Артериални хипертонии в детска възраст. Нови проблеми на Педиатрията. София, 1997, 93-121.

3. Flynn J. T. Differentiation Between Primary and Secondary Hypertension in Children Using Ambulatory Blood Pressure Monitoring. Pediatrics. 2002; 110.: 89-93.

4. Luma G., Spiotta R. Hypertension in Children and Adolescents. Am Fam Physician; 2006;73:1158-68.

5. Lurbe E., Redon J. Secondary Hypertension in Children and Adolescents. In Secondary Hypertension. Clinical Presentation, Diagnosis and Treatment. Ed. George Mansoon, Humana Press. Totowa, New Jersey, 2004, 279-303.

6. National High Blood Pressure Education Program Working Group on High Blood Pressure in Children and Adolescents. The fourth report on the diagnosis, evaluation, and treatment of high blood pressure in children and adolescents. Pediatrics. 2004; 114 (2 suppl 4th Report): 555-576

7. Norwood VF. Hypertension. Pediatr Rev 2002;23(6):197-208

8. Robinson R.,. Batisky D, John H at al. Significance of Heritability in Primary and Secondary Pediatric Hypertension Am. J. Hypert. 2005;18, (7): 917-921

9. Taler SJ. Secondary causes of hypertension. Primary Care: Clinics in Office Practice. 2008;35(3):489-500.

10. van Schalkwyk and Turner. Diagnosing Hypertension in Children and Adolescents. JAMA 2008;299:168-168. 